\title{
Cloud Computing Vis-à-Vis Agricultural Development towards Digital and Smarter Agricultural Informatics Practice
}

\author{
P. K. Paul ${ }^{1}$, R. R. Sinha ${ }^{2}$, P. S. Aithal ${ }^{3}$, Ricardo Saavedra ${ }^{4}$, Bashiru Aremu ${ }^{5}$, and S. Mewada ${ }^{6}$ \\ ${ }^{1}$ Executive Director, MCIS, Department of CIS, Information Scientist (Offg.), Raiganj University, India \\ ${ }^{2}$ Pro Vice-Chancellor (Asian Region), Commonwealth Vocational University, Kingdom of Tonga, Oceania \\ ${ }^{3}$ Vice-Chancellor, Srinivas University, Karnataka, India \\ ${ }^{4}$ Director \& Chair, International Inter-University Programs, Azteca University, México, North America \\ ${ }^{5}$ Vice-Chancellor, Crown University, Intl. Chartered Inc. (CUICI) Argentina Campus, South America \\ ${ }^{6}$ President, International Scientific Research Organization for Science, Engineering \& Technology, India \\ E-mail: pkpaul.infotech@gmail.com
}

\begin{abstract}
Cloud computing is an emerging and technologies within the Information Technology field and also technological era. Cloud Computing is used in almost all sectors, fields, organizations and institutions; where Information Technology is used. Cloud computing deals with the delivery of computing infrastructure, application and many need based collaboration viz. hardware, software, networks, storage, interfaces as a service by the internet and similar systems. Cloud Computing is also known as virtualization technology as it supports from the remote places depending upon the needs of the users and from the centralized unit and systems. It also allows healthy computing services including storage, memory, processing with many advantages and facilities with several platforms; hence it is become widely recognized around the world. Most importantly also offers many add on facilities with low cost implementation for the infrastructure. Cloud Computing enables payment depending upon the need of the organization, client and institutions, and facilities offered. It also acts as virtual hardware and also provides elasticity, network based services. Among the stakeholders of Cloud Computing; the most important are growing is Agriculture Sectors. It is useful in pre production and post production of the agricultural systems. This paper talks about the basics of Cloud computing including current and future applications in agriculture and allied domains. Paper also deals with the issues, challenges of Cloud computing in agro and allied domain in brief. Paper also suggested few concerns on Cloud Computing application in smarter agriculture dealing and Agriculture Informatics is also been provided, herewith.
\end{abstract}

Keywords: Cloud Computing, Information Technology, Agriculture, Agricultural Sciences, Smart Agriculture, Digital Agriculture, IT Applications in Agriculture

\section{INTRODUCTION}

Cloud Computing offers various advantages than conventional information technology practice. Moreover, it offers various kinds of value added services and following are some important characteristics in this regard

1. Cloud computing broken down, three important segments viz. being application, storage and connectivity.
2. Cloud computing mainly depends on the internet or networks systems for its round o'clock services and facilities.

3. It is responsible for the creation of the environment of the Grid Computing; due to its structure.

4. Cloud Computing depends on various kinds of parameters and among these continuous and robust internet and broadband services are required.

5. Hassle free engagement information technology support is possible with Cloud Computing practice.

6. With Cloud Computing support the hardware, as well as software, can get the users, easily with the services opt for.

Cloud Computing is a valuable name in current information and community technology world and making easier the knowledge and digital society by offering knowledge based services and promoting the same [2], [17], [31]. Knowledge Management is the core of knowledge Society and in this context, Cloud Computing is considered as an important technology. It is a kind of utility computing and can be beneficial in workload management and demand fulfilment of many organizations as they are using this technology, directly and indirectly. It helps in healthy and easiest migration, deployment. Today it is applicable in diverse areas and sectors including business, government, education, healthcare, transportation and so on. Similarly, in agriculture and cultivation including such industrial sectors are also using Cloud Computing systems. As Information is driving force in agro sectors as well hence, these technologies are being used for better solutions and systems. To keep updating, doing the pre agricultural work and post agro work information and technologies are most common, and in this context, Cloud Computing infrastructure is a healthy tool for most of the countries. In many countries Governments are putting priorities on Cloud Computing and Virtualization based solutions; and in agriculture as well this is become common and increasing rapidly. Cloud Computing may helpful in cloud based agricultural information systems for enriched agro information services and technological and information infrastructure support. Refer, Fig: 1for more clarification on this. 


\section{OBJECTIVES}

The current paper entitled, Cloud Computing Vis-à-Vis Agricultural Development - towards Digital \& Smarter Agricultural Informatics Practice' is a theoretical paper and empirical in nature and deals with the following aim and objectives -

1. To know about the basics of Cloud Computing including evolution, foundation and nature in brief.

2. To get the knowledge on types and emergence of Cloud Computing and Virtualization Technology, in brief.

3. To learn about the basic as well as service emerging models in respect of Cloud Computing and Technology

4. To learn about the Agricultural Informatics practice including basics and emergence in agricultural sectors.

5. To get the knowledge on the basic Cloud Computing applications in agriculture and allied domains

6. To learn about the Cloud Computing emerging applications and possibilities in agriculture and allied domains

7. To learn about the Challenges, Issues and concerns on Cloud Computing applications in agriculture and allied domain.

\section{METHODS}

The present work as theoretical in nature, thus it concerns with the studies with secondary sources. For doing this work, various secondary works have been consulted viz. Cloud Computing, IT and Computing, Agricultural Sciences, Agro Informatics. Further, works related to these topics on primary sources also been gathered, analyzed and reported in this work. Further, for doing this work Cloud Computing company's current offering and services also been mapped through their websites and various contemporary report provided by the Government and different agencies, etc.

\section{CLOUD COMPUTING AN OVERVIEW}

The society is changing rapidly and even its stakeholders with the effect of Information Technological development. Industries and organizations are the key users of Information Technology practice by its different sub fields and technologies viz. Web Technology, Database Technology, Multimedia Technology, Software Technology, Networking Technology, etc [7], [26], [38]. And these are highly used in the design and development of the Information Systems of various kinds. Within Information Technology some of emerging includes the Cloud Computing, Big Data Technologies, Human Computer Interaction, Data Analytics, Robotics and AI, etc. And within these, emerging Cloud Computing and Virtualization can be considered as an important one. Cloud computing making virtual presence or availability of the Information Technology tools and systems by using internet infrastructure. The following are core types of Cloud Computing.

\section{A. Public Cloud Computing}

In this kind of cloud computing, the IT based services are offered by the internet from the remote place. And it is considered as one of the important and most used Cloud based Services. This kind of service comes from the internet infrastructure, so here the concern of security is noticeable.

\section{B. Private Cloud Computing}

Private Cloud Computing is normally builtin an organization based on the need of the user. It is sometimes used for dealing the private and confidential data. This also closely refer to as Infrastructure as a Services.

\section{Hybrid Cloud Computing}

The combination of both Public Cloud Computing and Private Cloud Computing is called Hybrid Cloud Computing. It is one of the important computing methods and uses in the case to case basis.

Hence cloud is an advanced Information Technology based tool responsible for the offering of software, infrastructure, platform, storage and database, systems, security services, etc by the remote based systems. The services under cloud computing specifically nomenclature as under-

1. Software as a Service

2. Infrastructure as a Service

3. Storage as a Service

4. Platform as a Service

5. Security as a Service, etc

Public cloud was primarily as the most common and used but gradually Private Cloud and Hybrid Cloud Computing also valuable and uses throughout depending upon need. Regarding the services, initially, only Software as a Service, Storage as Services were mostly used but now other services even Security based services are also booming. 


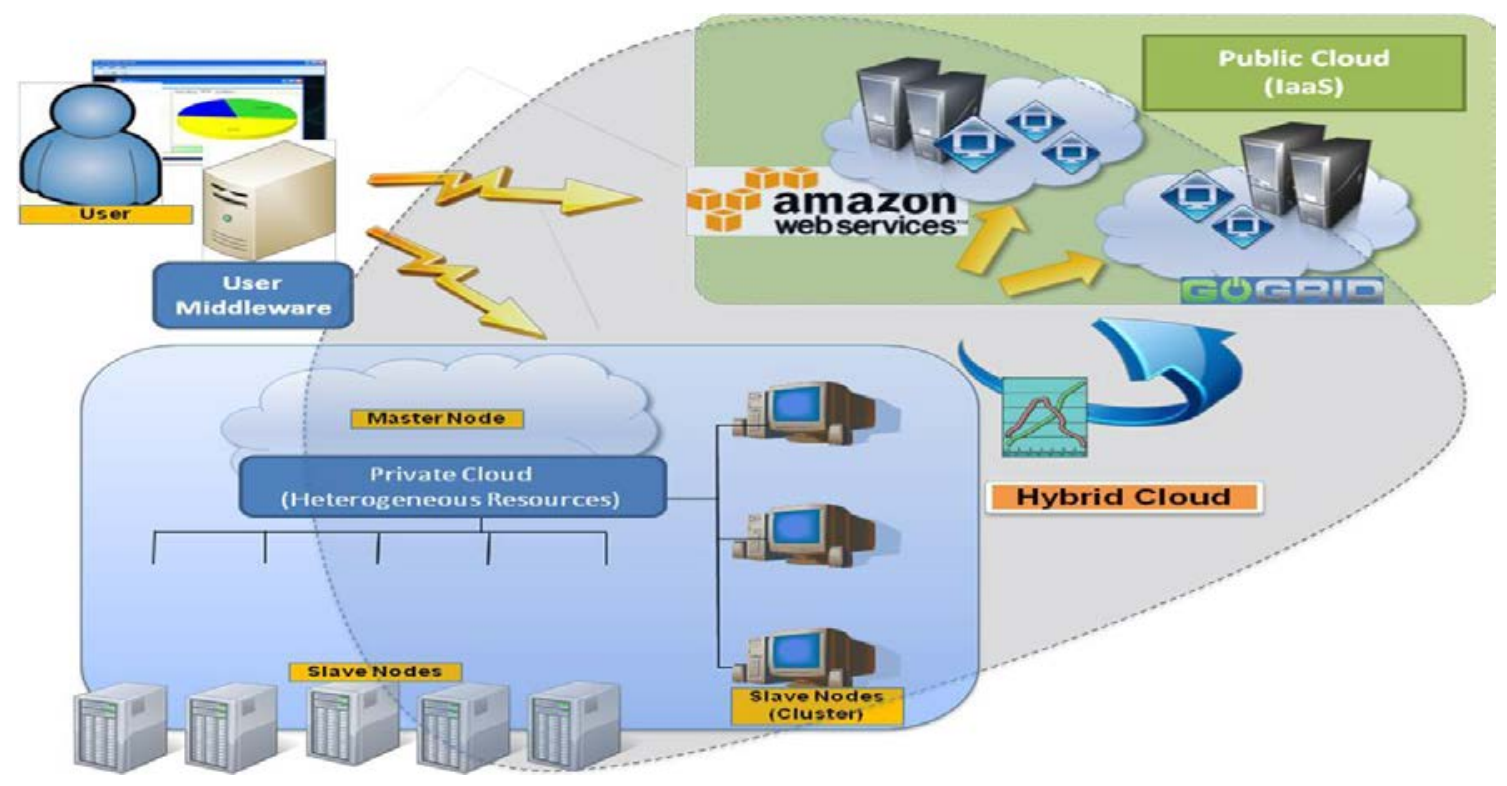

Fig.1 The whole network of cloud computing at a glance (enhanced from Garg \& Buyya)

\section{INFORMATION SCIENCES AND AGRICULTURE: THE BIRTH OF AGRICULTURAL INFORMATICS}

Information Sciences is a field of fields, incorporated with many similar subjects viz. Computing, Computer Science, Computer Applications, Computer Engineering, Information Technology, Information Systems, etc. It is an Applied Sciences and deals with various technologies to deal with information related problems and solutions. Information Science also takes the help of traditional or manual documentation systems for the information jobs leading to the collection, selection, organization, processing, management and dissemination of information. It is also Interdisciplinary and applicable in diverse areas and sectors (fields and subjects as well) viz. Healthcare, Business and Commerce, Education, Government, Agriculture, etc. As far as fields or subjects are concerned, it is applicable in various subjects and streams viz. Biology, Geography and Geo Sciences, Social Sciences, Mathematical Sciences, etc [3], [10], [30].

Hence Information Science is broader than Information Technology and responsible for the information and technological solutions for diverse organizations and institutions. The combination or merging of Information Science and Information Technology is referred to as 'Information Science \& Technology'. The applications of Information Science and Technology in Agricultural Sciences and sectors evolved the branch and subject, called 'Agricultural Information Technology' or 'Agricultural Informatics'. Agricultural Informatics is the solution for the technologies and information in regard to various activities of the agriculture viz. pre production agro related works and post production agro related works. It is responsible for enhancing productivity and helps in reaching smarter agricultural systems [4], [15], and [29].
Agricultural Informatics in recent past taking the integration and applications of various emerging sub technologies viz. Cloud Computing, Big Data Technologies, Human Computer Interaction, Data Analytics, Robotics and AI, etc and all these are dedicated to build Smart Agriculture perfectly.

\section{CLOUD COMPUTING APPLICATIONS IN AGRICULTURAL SECTORS}

Cloud computing services are increasing day by day with their various types and increasing model of services. Based on the organization types, the service models can vary and their uses as well. Agriculture as a broadest sector in occupation and business thus uses various types of Cloud Computing and various kinds of service models as well (refer Fig: 2). Among the diverse technological input from the Cloud Computing in respect of agriculture few important, are include (but not limited to)

1. Cloud Computing supports the data readiness all the time and irrespective of places, and hence for the agro related jobs, it is become valuable [5], [19], [37].

2. Agro Business deals with both local and international markets and thus local as well as global communication become easy and instant.

3. Cloud computing in generally helps in technological and information transfer and it led to the improvement of the economic development of the Nation. As far as Agriculture is concerned it is concentrated with such commitment. 
4. Hence solid applications of Agricultural Informatics in Agro and allied fields will help in enhancing the GDP; directly and indirectly.

5. Cloud Computing and other part of the Informatics and IT helps in ensuring better food transparencies and also food security level [6], [13], [14].

6. As, Cloud Computing will help in agro efficiency thus it will also help in the motivation of the farmers, agro professionals and researchers.

7. Uses of IT and Computing in Agriculture is concerned with the various technologies and thus it results in various technical issues but with the performances of the cloud and virtualization, it will reduce any technical issue [11], [18], [33].

8. The uses of Cloud Computing in basic and advanced agro related jobs can enhance the productivity as a result it may help in new jobs and occupations and will help in rural as well as urban movement as well.

9. Cloud Computing helps in anytime and anywhere data availability without delay and thus it helps; directly and indirectly in many contexts.

In the recent past, we have seen the aspects of loss of agricultural land, including the biodiversity all over. The changing weather conditions including weather condition is another result of climate change, the world population is another concern of the environment in the recent past. All these are connected with agriculture indirectly and in this context, the uses of IT can solve some problems and as an emerging Technology Cloud Computing uses is a worthy deal. More clearly it may prove to be a formidable asset [20], [24], [36].

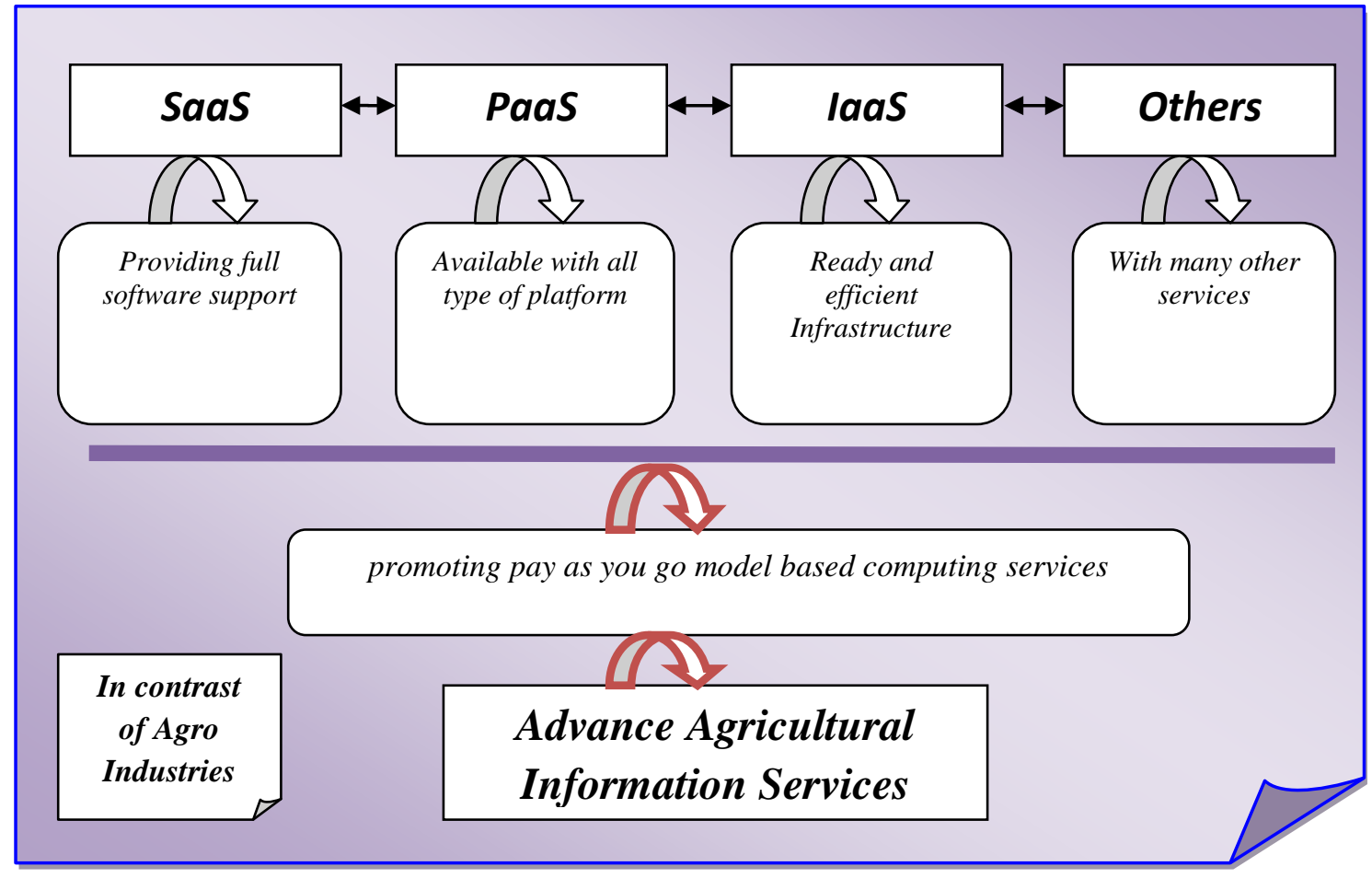

Fig.2 Cloud computing model and its platform

Cloud Computing can be helpful in better and healthy Agricultural Informatics practice that is responsible for the development of the whole ecosystem, from sensors and monitoring including data and field images of the agricultural field on the ground accurately. Using GPS coordinates the agro data mapping easy and here furthermore, sensors may detect the location and helpful in many contexts [21], [28], [34].

With the introduction of Cloud Computing in Agriculture, the Agriculture becomes more smarted and advanced thus the cultivator may utilize the cloud for the accessing of information and that can help in predictive analysis. This could lead the help in pre production including enhancement of agro products. Moreover, with cloud based systems the scenario and condition of the different markets are possible to learn easily. The prediction on weather conditions becomes easy with cloud connected database, it collects and stores data and later helps in better agro informatics practice and this ultimately helps in betterment in agricultural development towards digital agriculture. There are agricultural knowledge-based repositories increasing worldwide deals with information related to agriculture and by this, farmers can get help in diverse areas viz. in agro practices, healthy crops input, agricultural and environmental innovations, uses of the effective pesticides, better uses of seeds and fertilizers, etc. Moreover, expert advice on different platforms becomes easy with cloud based systems. Moreover, in post agro affairs like in supply chains and billing systems as well as Cloud Computing useful. The next sections have mentioned a detailed account of this. 


\section{A. Sector Specific Applications}

Cloud Computing is helpful in many information related and technological activities in respect of agriculture and some of the basic applications are include as follows

\section{B. Crop and Pre Production}

With the help of Cloud Computing, the information related to the crops can be gathered from the past and therefore this can help in cultivating and farming activities. Thus, it helps in better decision making. Moreover, the cloud enables the weather system will also helpful by cloud computing. This system is helpful in keeping/ storing the region-specific weather and climate related information; hence it is helping in weather fore casting so it is worthy for the farmers regarding the crop and other products.

\section{Soil Information}

Crop related aspects are closely associated with the soil information as well and thus with the applications of Cloud Computing it helps in drag the soil profile including the past history of the soil using cloud based repositories and thus ultimately helps in predicting the future trend of soil.

\section{Monitoring Growth}

Cloud Computing helps in more growth in various crops by providing various updates on crops, vegetables, plants and other agro products at regular intervals. This trend is possible by using Cloud based IoT systems. The drone technologies are uses in agriculture and these are connected with cloud systems. The current scenario gathering is possible using drone and cloud based integrated technologies [8], [25], [35].

\section{E. Gathering Farmers Data Using Cloud based Agro Networks}

With the help of Cloud Computing, the date of the farmers and cultivators can be captured as well as monitored. Hence cloud based Agricultural Network will help in gathering data of local as well as remote farmers with their current cultivating items, methods, etc. This will also help in finding the core agricultural areas and helps in decision making including the policymaking while with their strategies.

\section{F. Expert Consultation using Cloud}

With the cloud based systems and networks, the connected farmers can communicate each other and ask frequently. Moreover, by the use of Cloud Computing expert solutions on a specific problem in a real time situation is also possible to gather [1], [12], [22].

\section{E-COMMERCE AND BUSINESS ACTIVITIES}

With the help of Cloud Computing based agro systems not only advanced or urban farmers and small farming associations but also farmers from the rural areas able to sell their agro products directly to the market. Hence it will reduce the need for middleman in agro fields as well. Here Cloud based agricultural management system helps in better communication, market growth and complete post production activities including supply chain management systems. The latest information on various aspects viz. Weather condition, prices and current market, fertilizer, sowing of crops, etc. are possible to gather easily using the cloud.

1. Cloud Computing helps in enhancing agricultural information and data bank. Ultimately these will deal with various products such as crop, weather, soil, growth progress, farmer data, expert consultation, etc.

2. Cloud Computing helps in storing different kinds of information in different formats using a centralized cloud and available throughout [9], [27], [32].

3. Information on the aspects and concern viz. land, location and place; soil, crops, land, etc are possible with cloud based systems integrated with decision support systems.

4. Cloud Computing helps in higher integration as well as sharing of agricultural information including the products.

5. Cloud Computing is helpful in eliminating the farmer's limitations regarding the technological deal\& resources; as a result, agricultural technology services become easy.

6. Agricultural product marketing including supply chain management becomes easy with the Cloud Computing support in agro and allied fields.

\section{CHALLENGES AND ISSUES OF CLOUD BASED AGRO SYSTEMS: SOME CONCERN}

Though there are many advantages, benefits and usefulness in cloud computing but there are certain bottlenecks and for that implementing Cloud Computing in all the areas becomes difficult in some context. Implementing Cloud Computing in agriculture concern with the finance and commercial aspects. Hence for implementing this huge initial fund is important. Furthermore, the issues of IT laws, Cyber Laws, etc are also an important concern. The security of data and services is another issue according to some experts. Hence well known and practicing and leader in the market is expected.

As Cloud Computing runs with high-speed internet connection so there should be properly backed up at that moment with speed and constant support. Networked Systems and Services are also very important in Smart Agriculture using Cloud Computing. Skilled manpower is 
another important issue that can consider as an important challenge in incorporating Cloud Computing in Agriculture. It needs the manpower for the designing, development and operation of the Cloud based Agricultural Systems. Moreover, skills and training are required of different stakeholders and farmers/ cultivators as well.

Some of the important and leading countries that using Cloud Computing for building Smart Agriculture are include - Japan, China, South Korea, USA, Singapore, etc. Apart from the countries in Asia and America, even East Africa also doing well in Cloud Computing practice in Agriculture in the recent past. Even India is also doing well with respect to Cloud Computing implementation in Agriculture. Surprisingly Himalayan country Bhutan also started using ICT in agriculture and emerging technologies as well.

\section{SUGGESTIONS \& RECOMMENDATIONS}

The uses of Cloud Computing though have remarkable benefits and advantages but we need to care of more about the issues to help in core smarter agriculture that will be intelligent, farmers, users and environment friendly.

1. As Cloud Computing is managed and maintenance third party, data security issues need to handle properly.

2. The issues on Cloud System's administrator accountability also need to check on.

3. Farmer is unknown for cloud computing technology

4. There is no control over physical systems sometimes and this can lead the attraction to hackers. And this aspect needs to handle properly.

5. Internet and network connectivity should be robust, secure and with speed.

6. Cloud Computing requires healthy and constant internet connection and electronic support as well.

7. Platform of the system may be difficult in sometimes and this can lead the problems with the farmers. Hence proper guide manual should be followed.

8. Training programs are essential for ICT in Agriculture and better Agricultural Informatics practice and in Cloud Computing practice in agro areas.

9. Education leading to degrees, researches, etc are essential to boost Cloud Computing based Agro Information Systems, Agriculture and similar activities.

10. Proper policies and framework etc are essential in better and healthy dealing of Cloud Computing in agriculture.

\section{CONCLUSION}

Cloud Computing and similar technologies viz. Big Data, Grid Computing, Scalable Computing, HCI, Robotics, etc increasing rapidly with growing utilization in diverse areas. And Agriculture is not an exception of this. Information Systems and infrastructure are positively possible using cloud integration and this will help in better Agricultural Informatics practice in a different context. India, as a developing nation has a large market and thus agro based cloud services and cloud enriched products become easy to get in some context or rather than other developing countries. Many MNC's, government initiatives on digital revolution and infrastructure are highly appreciating. Though there are certain issues and concerns such as proper policy, regulation, framework, availability of manpower, etc, and by overcoming such a healthy Smarter, Advanced, Digital and Sustainable Agriculture become possible.

\section{REFERENCES}

[1] A.Z.Abbasi, N. Islam and Z.A. Shaikh, "A review of wireless sensors and networks' applications in agriculture," Computer Standards \& Interfaces, Vol. 36, No. 2, pp. 263-270, 2014

[2] T. Adão, et.al., "Hyperspectral imaging: A review on UAV-based sensors, data processing and applications for agriculture and forestry,”. Remote Sensing, Vol. 9, No. 11, pp. 1110-1120, 2017.

[3] K.E.Adetunji and M.K. Joseph, "Development of a Cloud-based Monitoring System using 4duino: Applications in Agriculture”. In 2018 International Conference on Advances in Big Data, Computing and Data Communication Systems (icABCD) (pp. 4849-4854), 2018

[4] T.Ahmad, S.Ahmad and M. Jamshed, "A knowledge based Indian agriculture: With cloud ERP arrangement”. In 2015 International Conference on Green Computing and Internet of Things (ICGCIoT), pp. 333-340, October, 2015

[5] B.A. Aubert, A.Schroeder and J. Grimaudo, "IT as enabler of sustainable farming: An empirical analysis of farmers' adoption decision of precision agriculture technology," Decision support systems, Vol.54, No.1, pp. 510-520, 2012

[6] S.M.Babu, A.J. Lakshmi and B.T. Rao, “A study on cloud based Internet of Things: CloudIoT”. In 2015 global conference on communication technologies (GCCT) (pp. 60-65). IEEE, April, 2015

[7] S. Balamurugan, N. Divyabharathi, K. Jayashruthi,M. Bowiya, R.P.Shermy and R. Shanker, "Internet of agriculture: Applying IoT to improve food and farming technology", International Research Journal of Engineering and Technology (IRJET), Vol. 3, No. 10, pp.713-719, 2016

[8] C.Bauckhage and K. Kersting, "Data mining and pattern recognition in agriculture,” KI-Künstliche Intelligenz, Vol. 27, No. 4, pp. 313324, 2013

[9] K. Chandraul and A. Singh, “An agriculture application research on cloud computing” International Journal of Current Engineering and Technology, Vol. 3, No. 5, pp.2084-2087, 2013

[10] H. Channe, S. Kothari and D. Kadam, "Multidisciplinary model for smart agriculture using internet-of-things (IoT), sensors, cloudcomputing, mobile-computing \& big-data analysis,” Int. J. Computer Technology \& Applications, Vol. 6, No. 3, pp. 374-382, 2015

[11] S.S. Gill,I. Chana and R. Buyya, "IoT based agriculture as a cloud and big data service: the beginning of digital India," Journal of Organizational and End User Computing (JOEUC), Vol. 29, No. 4, pp.1-23, 2017

[12] R.Gómez-Chabla, K.Real-Avilés,C. Morán, P. Grijalva and T. Recalde, "IoT Applications in Agriculture: A Systematic Literature Review". In 2nd International Conference on ICTs in Agronomy and Environment, pp. 68-76, 2009

[13] M.S.Goraya and H. Kaur , “ Cloud computing in agriculture,” HCTL Open International Journal of Technology Innovations and Research (IJTIR),Vol. 16, pp. 2321-1814, 2015.

[14] E. Guardo, A. Di Stefano, A. La Corte, M. Sapienza and M.Scatà, “A fog computing-based iot framework for precision agriculture.,” Journal of Internet Technology, Vol. 19 , No.5 , pp. 1401-1411,2018.

[15] M. Hori, E. Kawashima and T. Yamazaki, "Application of cloud computing to agriculture and prospects in other fields,” Fujitsu Sci. Tech. J, Vol. 46, No. 4, pp. 446-454, 2010

[16] S.S. Kamble, A. Gunasekaran and S.A. Gawankar, “Achieving sustainable performance in a data-driven agriculture supply chain: A review for research and applications," International Journal of Production Economics, Vol. 219, pp. 179-194, 2020

[17] R. Kajol and K.K. Akshay, “Automated Agricultural Field Analysis and Monitoring System Using IOT. International Journal of 
Information Engineering and Electronic Business,” Vol. 11, No.2, 2018

[18] A.Khattab, A.Abdelgawad and K. Yelmarthi, "Design and implementation of a cloud-based IoT scheme for precision agriculture," In 2016 28th International Conference on Microelectronics, pp. 201-204, IEEE, December, 2016

[19] S.Liu,L. Guo, H. Webb, X. Ya and X. Chang, " Internet of Things monitoring system of modern eco-agriculture based on cloud computing,” IEEE Access, Vol. 7, pp. 37050-37058, 2019

[20] B. Manos,N. Polman and D.Viaggi, "Agricultural and environmental informatics, governance and management: Emerging research applications,” Z. Andreopoulou (Ed.). IGI Global (701 E. Chocolate Avenue, Hershey, Pennsylvania, 17033, USA, 2011

[21] J. Muangprathub, N.Boonnam, S. Kajornkasirat, N. Lekbangpong, , A. Wanichsombat and P. Nillaor, "IoT and agriculture data analysis for smart farm”. Computers and electronics in agriculture, Vol. 156, pp. 467-474, 2019

[22] A. Na and W. Isaac, Developing a human-centric agricultural model in the IoT environment. In 2016 International Conference on Internet of Things and Applications (IOTA) pp. 292-297, IEEE, January, 2016

[23] A. Nayyar and V. Puri, "Smart farming: IoT based smart sensors agriculture stick for live temperature and moisture monitoring using Arduino, cloud computing \& solar technology". In Proc. of The International Conference on Communication and Computing Systems (ICCCS-2016) (pp. 978-990), 2016.

[24] T. Ojha, S.Misra and N.S. Raghuwanshi, "Wireless sensor networks for agriculture: The state-of-the-art in practice and future challenges." Computers and Electronics in Agriculture, Vol. 118, pp. 66-84, 2015

[25] M.F.Othman and K. Shazali, "Wireless sensor network applications: A study in environment monitoring system”. Procedia Engineering, Vol. 41, pp. 1204-1210, 2012

[26] B. Ozdogan, A. Gacar and H. Aktas, "Digital agriculture practices in the context of agriculture 4.0," Journal of Economics Finance and Accounting, Vol. 4, No. 2, pp. 186-193, 2017

[27] Pau1, Prantosh Kumar Minakshi Ghosh and Dipak Chaterjee, "Information Systems \& Networks (ISN): Emphasizing Agricultural Information Networks with a case Study of AGRIS”.Scholars Journal of Agriculture and Veterinary Sciences, Vol .1, No. 1, pp. 38-41, 2014.
[28] Paul and Prantosh Kumar, "Information and Knowledge Requirement for Farming and Agriculture Domain”.International Journal of Soft Computing Bio Informatics, Vol. 4, No. 2, pp. 80-84, 2013

[29] Paul, Prantosh Kumar etal, “Agricultural Problems in India requiring solution through Agricultural Information Systems: Problems and Prospects in Developing Countries," International Journal of Information Science and Computing,Vol. 2, No.1, pp. 33-40.

[30] Paul and Prantosh Kumar etal. "Cloud Computing and Virtualization in Agricultural Space: A Knowledge Survey”. Palgo Journal of Agriculture, Vol. 4, No. 2, pp.202-206, 2016

[31] Paul and Prantosh Kumar etal, "Information and Communication Technology and Information: their role in Tea Cultivation and Marketing in the context of Developing Countries-A Theoretical Approach". Current Trends in Biotechnology and Chemical Research,Vol. 5, No. 2, pp. 55-161, 2015

[32] T. Rezník, K.Charvát, V. Lukas, K. Charvát Jr,S. Horáková and M. Kepka, "Open data model for (precision) agriculture applications and agricultural pollution monitoring". In EnviroInfo and ICT for Sustainability 2015. Atlantis Press, Sept. 2015

[33] M. Roopaei, P. Rad and K.K.R. Choo, "Cloud of things in smart agriculture: Intelligent irrigation monitoring by thermal imaging,".IEEE Cloud computing, Vol. 4, No.1, pp. 10-15, 2015

[34] F. TongKe, "Smart agriculture based on cloud computing and IOT," Journal of Convergence Information Technology, Vol. 8, No. 2, pp. 210-216, 2013

[35] G. Tsekouropoulos, Z. Andreopoulou, C. Koliouska, T.Koutroumanidis and C. Batzios, "Internet functions in marketing: multicriteria ranking of agricultural SMEs websites in Greece" Agrárinformatika/journal of agricultural informatics, Vol. 4, No. 2, pp. 22-36, 2013.

[36] M.A. Zamora-Izquierdo, J. Santa, J.A. Martínez, V. Martínez, and A.F. Skarmeta, " Smart farming IoT platform based on edge and cloud computing”. Biosystems engineering, Vol. 177, pp. 4-17, 2013

[37] Y. Zhu, D. Wu and S. Lil, "Cloud computing and agricultural development of China: theory and practice," International Journal of Computer Science Issues (IJCSI), Vol.10, No. 1,pp. 7-18, 2013 